University of Nebraska - Lincoln

DigitalCommons@University of Nebraska - Lincoln

Architectural Engineering -- Faculty Publications

Architectural Engineering and Construction,

Durham School of

3-2006

\title{
Room Acoustics Computer Modeling: Study of the Effect of Source Directivity on Auralizations
}

\author{
Michelle C Vigeant \\ University of Nebraska - Lincoln \\ Lily M. Wang \\ University of Nebraska - Lincoln, Iwang4@unl.edu \\ Jens Holger Rindel \\ Technical University of Denmark
}

Follow this and additional works at: https://digitalcommons.unl.edu/archengfacpub

Part of the Architectural Engineering Commons

Vigeant, Michelle C; Wang, Lily M.; and Rindel, Jens Holger, "Room Acoustics Computer Modeling: Study of the Effect of Source Directivity on Auralizations" (2006). Architectural Engineering -- Faculty

Publications. 16.

https://digitalcommons.unl.edu/archengfacpub/16

This Article is brought to you for free and open access by the Architectural Engineering and Construction, Durham School of at DigitalCommons@University of Nebraska - Lincoln. It has been accepted for inclusion in Architectural Engineering -- Faculty Publications by an authorized administrator of DigitalCommons@University of Nebraska Lincoln. 


\title{
Room Acoustics Computer Modeling: Study of the Effect of Source Directivity on Auralizations
}

\author{
Michelle C. Vigeant ${ }^{1}$, Lily M. Wang ${ }^{1}$, and Jens Holger Rindel ${ }^{2}$ \\ ${ }^{1}$ Architectural Engineering Program, University of Nebraska - Lincoln, Peter Kiewit \\ Institute, 1110 S. $67^{\text {th }}$ St., Omaha, NE 68182-0681; PH (402) 554-2038; FAX (402) \\ 554-2080; email: mvigeant@unlnotes.unl.edu; email: lwang4@unl.edu \\ ${ }^{2}$ Acoustic Technology, Oersted-DTU, Technical University of Denmark, Building \\ 352, DK-2800 Kgs. Lyngby, Denmark; email: jhr@oersted.dtu.dk
}

\section{Abstract}

Auralizations are very useful in the design of performing arts spaces, where auralization is the process of rendering audible the sound field in a space, in such a way as to simulate the binaural listening experience at a given position in the modeled space. One of the fundamental modeling inputs to create auralizations is the source directivity. Standard methods involve inputting the measured source directivity, calculating the impulse response and convolving it with a single channel anechoic recording. An initial study was conducted using this method and the results showed significant differences in reverberation time and clarity index when using a directional versus omni-directional source. Further research was conducted focusing on an alternative method of modeling source directivity that involves multi-channel anechoic recordings to create auralizations. Subjective tests were conducted comparing auralizations made with one, four and thirteen channels, with three different instrument types and subjects rated differences in realism. An analysis of variance (ANOVA) was carried out to determine the effect of the number of channels and instrument on realism. The primary result from this study was that subjects rated the auralizations made with an increasing number of channels as sounding more realistic, indicating that when more accurate source directivity information is used a more realistic auralization is possible.

\section{Introduction}

Room acoustics is the study of sound propagation indoors and is often studied using modeling software. Several software packages exist that can be used for room acoustics calculations, including Odeon and CATT Acoustics. The same general procedure is used in all programs. The user initially must create the geometry of the 
space that they wish to model either within the program or by importing a three dimensional CAD drawing. The next step is to assign the material properties to each surface, which includes the degree of absorption and diffusion. The source and receiver locations are assigned, where the source is typically at the front of the room or on the stage and the receivers are dispersed in the remainder of the space in typical listening positions. The directional characteristics of the source are then assigned. Finally, the room impulse response (RIR) is calculated from which room acoustics parameters, including reverberation time (T30) and clarity index, can be derived. The RIR can also be used to create auralizations, which is the process of rendering audible the sound field in a space, in such a way as to simulate the binaural listening experience at a given position in the modeled space (Kleiner et al, 1993). The RIR is convolved with a dry (anechoic) recording to produce an aural simulation of the modeled space.

Source directivity is a very important input parameter and is often overlooked. Most users typically assign the source to have an omni-directional radiation pattern, which is graphically realized as a sphere emitting sound evenly in all directions. In order to obtain more realistic results, actual measured directivities should be input into the program. Meyer was the first researcher to compile a comprehensive data set of instrument directivities (Meyer, 1975) and this data is currently available on the Physikalisch-Technische Bundesanstalt website (PTB, 2005).

Previous work has examined the subjective effects of varying source directivity in auralizations. Dalenbäck studied subjective impressions of auralizations using two different loudspeakers with different directivities: a "monitor-type speaker" and a "constant-directivity horn" (Dalenbäck et al, 1993). The study did not isolate directivity, as the loudspeaker location was not held constant between trials. However, subjects did correctly identify differences in clarity and reverberation and he concluded that they could detect differences in the directivities. Giron found similar results when he conducted subjective studies comparing different degrees of detail of source directivity, however he had a small sample size and the results could not be statistically verified (Giron, 1996).

Further work evaluating source directivity both subjectively and objectively has been done by Otondo and Rindel. They examined the effects of using average directivities versus tone specific directivities for three instruments on the calculations in a modeled hall (Otondo and Rindel, 2004). They examined the distribution of the following room acoustics parameters in the model: sound pressure level (SPL), clarity index (C80), lateral energy fraction (LF80) and early decay time (EDT). Clear differences in the parameters' distributions emerged between the average and tone specific directivities. The results of the subjective testing revealed that subjects found differences in loudness for all instruments and reverberation for two of the instruments.

Otondo and Rindel also examined a new method for incorporating source directivity into auralizations by using multi-channel auralizations (Otondo and 
Rindel, 2005). This method involves making multi-channel anechoic recordings of short melodies. They made recordings using a thirteen channel recording set-up, with eight microphones in the horizontal plane and five in the vertical. To create a multichannel auralization, an omni-directional source is subdivided into sections to represent each recording channel. The RIR is then calculated for each section and convolved with the appropriate recording channel. The final auralization is created by mixing the separate channel auralizations together. Subjects compared auralizations made with one, two, five and ten channels in terms naturalness of timbre and spaciousness. Overall, the subjects found the auralizations made with an increasing number of channels to sound more natural, but did not detect a significant difference in spaciousness.

This paper discusses further work investigating the effect of source directivity on the results of computer modeling. Two studies are described, the first of which compares the objective and subjective results of using an omni-directional source and an extremely directional source for computer model simulations. The second study explores the subjective impressions of multi-channel auralizations made with recordings from three different instrument types.

\section{Study 1}

The purpose of Study 1 was to determine if there are objective and subjective differences when calculating the RIR with an omni-directional and a directional source. The directional source used was an extremely directional source, which beamed sound in one sixteenth of a sphere and is referred to as a "sixteenth-tant" source, as shown in Figure 1.

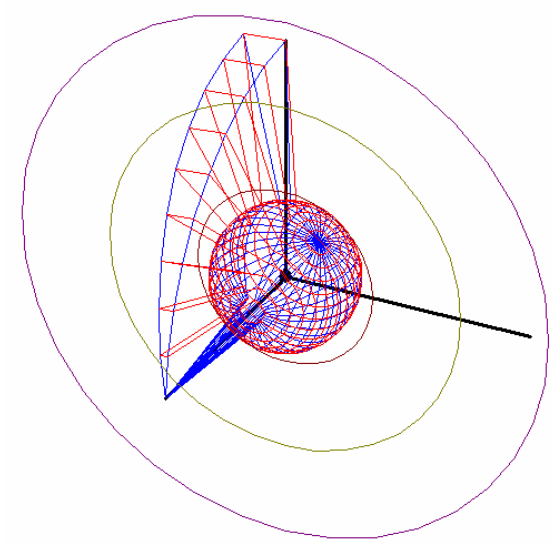

Figure 1. Sixteenth-tant source which radiates sound from $1 / 16^{\text {th }}$ of sphere.

A simple room was modeled in Odeon room acoustics modeling software (Figure 2). The three source positions used were located on the stage and three receiver positions were scattered throughout the audience area. RIRs were calculated for each source/receiver combination for both source directivities and the resulting room 
acoustics parameters were calculated. The parameters evaluated in this study were reverberation time (T30) and clarity index (C80).

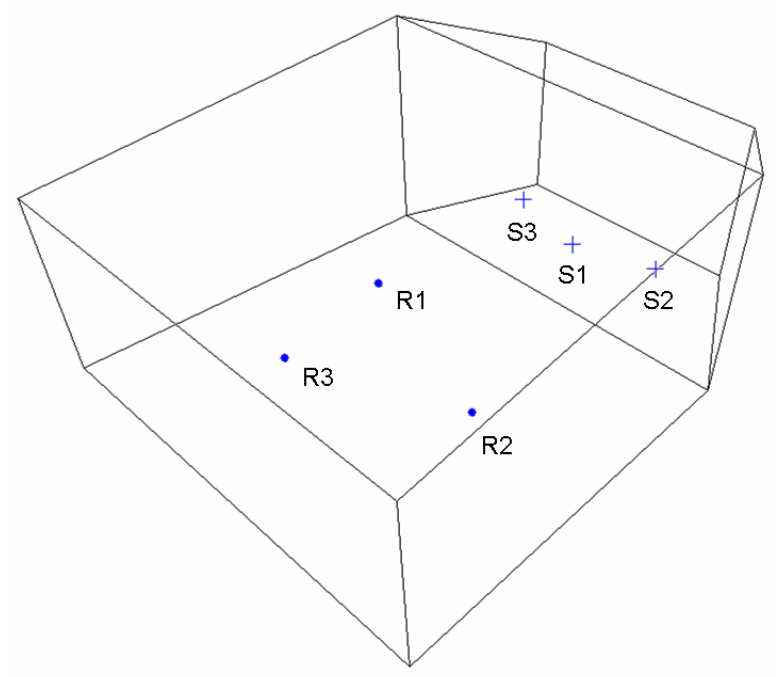

Figure 2. Hall geometry and the source and receiver positions.

The RIRs from two of the nine different source/receiver combinations, S1/R3 and S3/R2, which produced large differences in T30, were convolved with anechoic recordings to produce auralizations. Musical recordings from violin, piano and singing voice were used. Subjective tests were done with 28 participants, using paired comparisons. Subjects were presented with a pair of auralizations over headphones and asked if they were the same or different, and if different which auralization was more realistic, had higher clarity, and higher reverberance.

\section{Results and discussion of study 1}

The average difference in T30 calculated from the RIR of the sixteenth-tant and omni-directional sources was $4.8 \%$, averaged across all octave bands $(63 \mathrm{~Hz}$ to 8 $\mathrm{kHz}$ ) and all source receiver positions, which is slightly below the just noticeable difference (JND) of $5 \%$ (Bork, 2000). When considering the two source/receiver combinations used for the auralizations, the average differences across frequencies for $\mathrm{S} 1 / \mathrm{R} 3$ and $\mathrm{S} 3 / \mathrm{R} 2$ were $3.6 \%$ and $7.7 \%$, respectively. In general, the differences in the T30 for S1/R3 were below the JND, while for S3/R2 the differences were greater than the JND and should be detectable, as shown in Figure 3.

The average difference in clarity across all octave bands and all receiver positions was $1.6 \mathrm{~dB}$, while for positions $\mathrm{S} 1 / \mathrm{R} 3$ and $\mathrm{S} 3 / \mathrm{R} 2$ the average differences were $1.2 \mathrm{~dB}$ and $0.8 \mathrm{~dB}$ respectively. The JND for clarity is $1 \mathrm{~dB}$ (Bork, 2000), thus the differences for $\mathrm{S} 1 / \mathrm{R} 3$ should be audible. The results for these two positions are shown in Figure 4. 


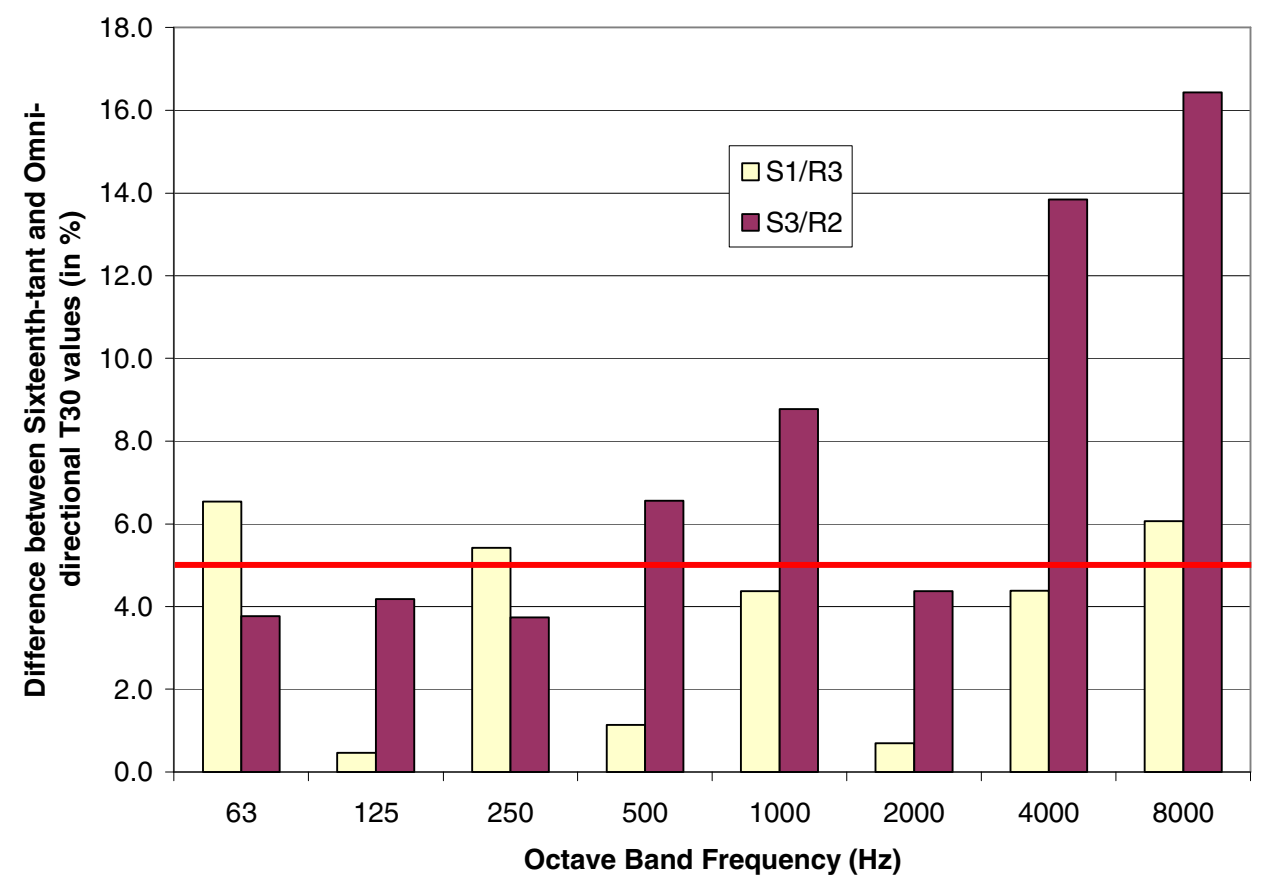

Figure 3. The percent difference between the T30 values of the sixteenth-tant source as compared to the omni-directional source for the two positions S1/R3 and $\mathbf{S 3} / \mathbf{R 2}$. The solid line at $5 \%$ indicates the just noticeable difference for $\mathbf{T 3 0}$.

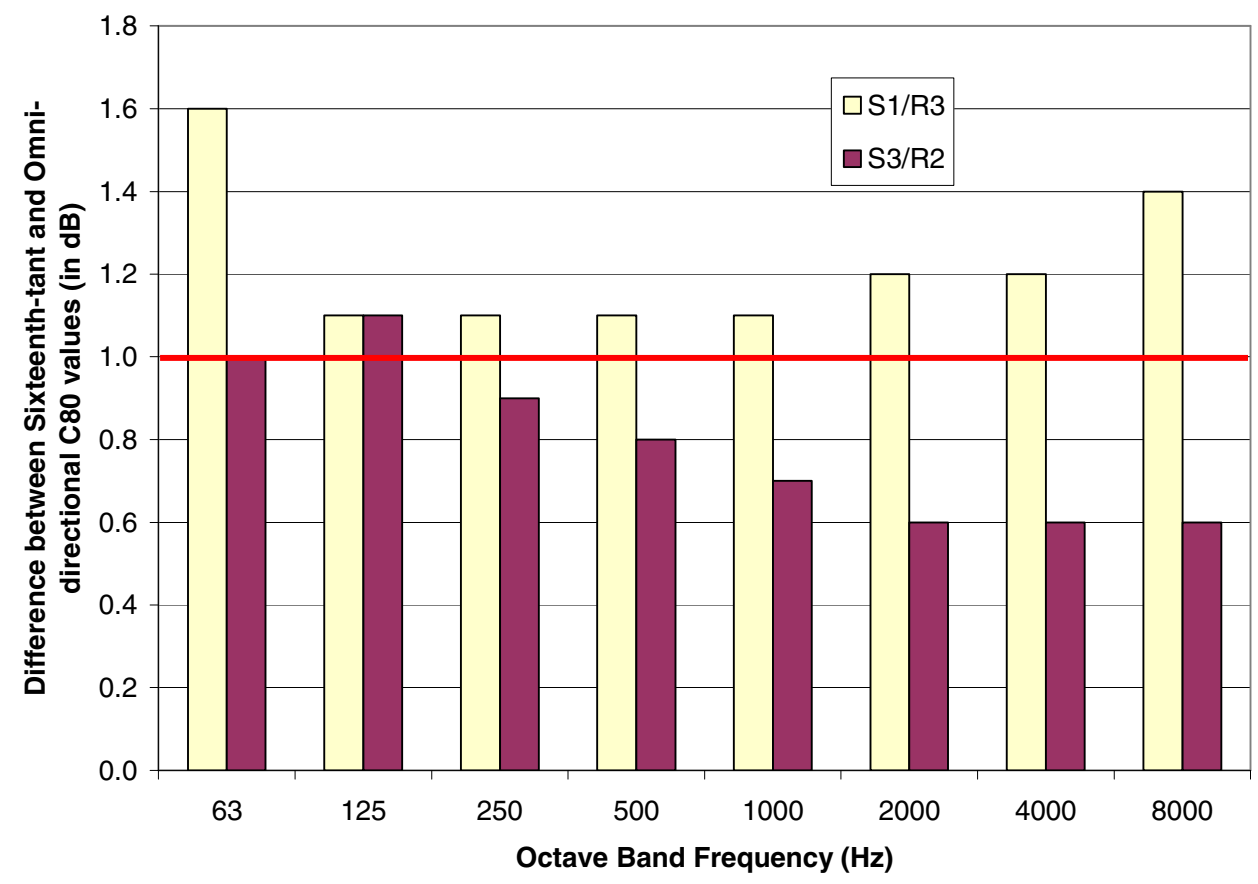

Figure 4. The difference between the clarity index $(\mathrm{C80})$ values of the sixteenthtant source as compared to the omni-directional source for the two positions $\mathrm{S1} / \mathrm{R} 3$ and S3/R2. The solid line at $1 \mathrm{~dB}$ indicates the just noticeable difference for C80. 
The results from the subjective study revealed that subjects could consistently hear a difference between the auralizations made with an omni-directional and the sixteenthtant source and in general rated the omni-directional auralizations as sounding more realistic. Subjects did not identify differences in reverberance for the case of S1/R3, as expected since the difference was less than the JND, but for the case of S3/R2 subjects did perceive an increase in reverberance as predicted from the objective data. Similarly, subjects did not detect a difference in clarity for S3/R2, but did detect an increase in clarity for S1/R3 as expected.

\section{Study 2}

The focus of the second study was multi-channel auralizations. Anechoic recordings of several instrumentalists using a 13-channel set-up (Figure 5) were made at the Technical University of Denmark by F. Otondo and J.H. Rindel (2005). Auralizations were created using single channel (position 1), four channel (positions $1,3,5$ and 7) and thirteen channel configurations. The room impulse responses were calculated with an omni-directional source for the single channel case, four quadrant sources, and thirteen thirteenths of a sphere, which are shown in Figure 6. Each RIR was convolved with the appropriate recording channel and then the individual channel auralizations were mixed together to create a final multi-channel auralization for the four and thirteen channel cases. The recordings used were short melodies captured separately from a flute, trombone, and violin.
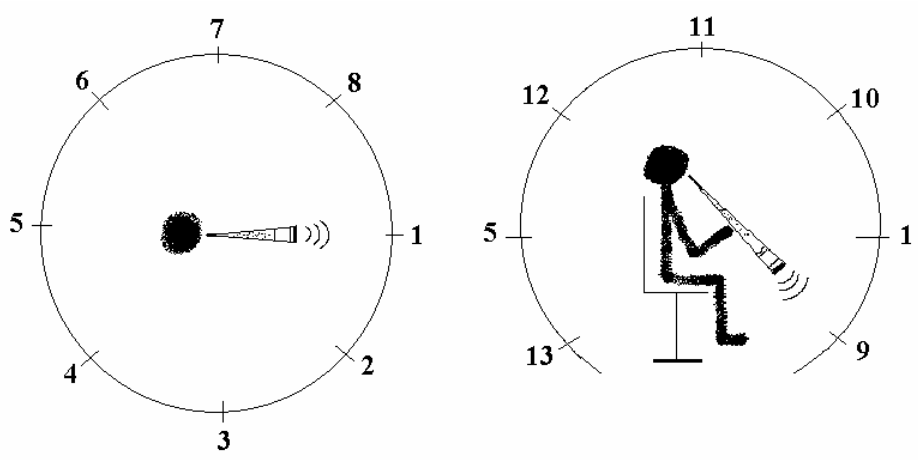

Figure 5. Anechoic recording set-up with 13 microphone positions. The figure on the left illustrates the horizontal plane, while the figure on the right illustrates the vertical plane, after Otondo and Rindel 2004. 


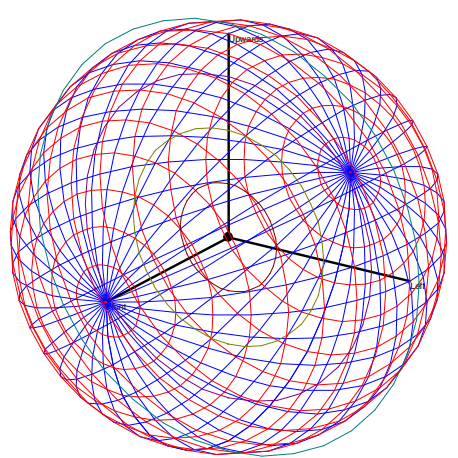

(a)

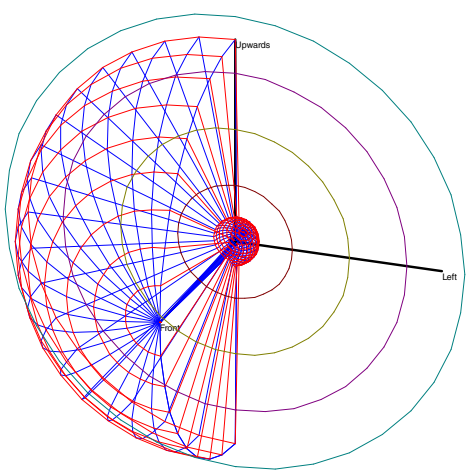

(b)

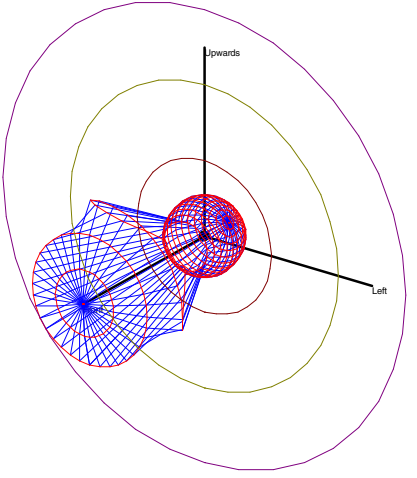

(c)

Figure 6. The source directivities used to calculate the room impulse responses:

a) Omni-directional source - 1 of 1 channel, b) Quadrant source - 1 of 4 channels, and c) Thirteenth source -1 of 13 channels.

A group of 29 musically trained subjects were presented auralizations over headphones made with 1, 4 and 13 channels with each of the three instruments. The subjects were asked to rate the realism of the tracks on a seven point scale, where 1 was very unrealistic and 7 was very realistic. The auralizations were presented in a random order to each subject and each auralization was presented twice to check for consistency of subjective ratings.

\section{Results and discussion of study 2}

An analysis of variance (ANOVA) was conducted on the results to determine if there is a significant relationship between the number of channels used in the auralizations and realism ratings. The independent variables in the analysis were number of channels, instrument, and repetition. A significant main effect of number of channels on realism was found $(\mathrm{F}(2,522)=16.35, \mathrm{p}<.05)$, as shown in Figure 7 . The general trend indicates that as the number of channels increase, the realism rating increases. Post hoc tests revealed that the differences in the ratings between 1 and 13 channels, and 4 and 13 channels are significant. 


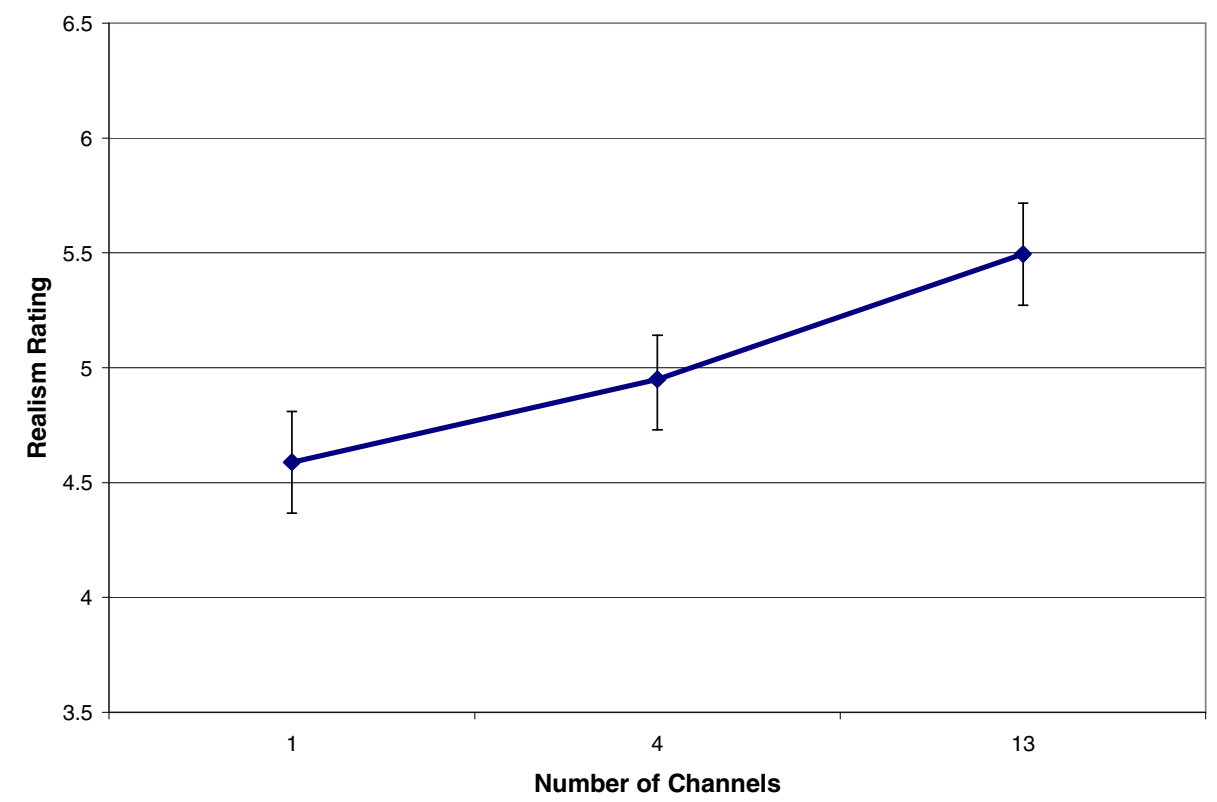

Figure 7. A plot of subjective realism rating versus number of channels. Number of channels was found to have a main effect on the realism ratings of the tracks at a 0.05 significance level. The results are averaged over all three instruments. The bars above and below the data points represent the $95 \%$ confidence intervals of the data points.

\section{Conclusion}

The purpose of this project was to investigate the importance of source directivity in room acoustics computer modeling. The initial study showed that there are objective differences in reverberation time and clarity index depending on whether an omni-directional or an extremely directional sixteenth-tant source is used. Subjective testing with auralizations supported these findings as subjects correctly identified when there were changes in both reverberance and clarity. In addition, subjects thought that the auralizations created with the omni-directional source sounded more realistic. The second study investigated the method of multi-channel auralizations with subjective testing. An analysis of variance of the results showed that subjects rated auralizations with an increasing number of channels as sounding more realistic. The results from both of these studies illustrate the importance of incorporating source directivity into room acoustics modeling for both objective and subjective studies. 


\section{References}

Bork, I. (2000). "A comparison of room simulation software - the second round robin on room acoustical computer simulation." Acustica 86(6), 943-956.

Dalenbäck, B. I., Kleiner, M., and Svensson, P. (1993). "Audibility of changes in geometric shape, source directivity, and absorptive treatment - experiments in auralization.” J. Audio Eng. Soc., 41(11), 905-913.

Giron, F. (1996). Investigations about the directivity of sound sources, Ph.D. dissertation, Ruhr-Universität Bochum.

Kleiner, M., Dalenback, B.I., and Svensson, P. (1993). “Auralization - an overview.” J. Audio Eng. Soc., 41(11), 861-875, (1993).

Meyer, J. (1978). Acoustics and the performance of music, Verlag Das Musikinstrument, Frankfurt/Main.

Otondo, F., and Rindel, J. H. (2004). "The influence of the directivity of musical instruments in a room." Acta Acustica united with Acustica, 90(6), 1178-1184.

Otondo, F., and Rindel, J. H. (2005). "A new method for the radiation representation of musical instruments in auralizations." Acta Acustica united with Acustica, 91(5), 902-906.

PTB. (2005). Instrument directivity data. http://www.ptb.de/en/org/1/17/173/richtchar.htm (Nov. 12 $\left.2^{\text {th }}, 2005\right)$. 